\title{
Alphabet Soup: Sagittal Balance Correction Osteotomies of the Spine-What Radiologists Should Know
}

\author{
(D)T. Takahashi, (DD. Kainth, DS. Marette, and (DD. Polly
}

\begin{abstract}
SUMMARY: Global sagittal malalignment has been demonstrated to have correlation with clinical symptoms and is a key component to be restored in adult spinal deformity. In this article, various types of sagittal balance-correction osteotomies are reviewed primarily on the basis of the 3 most commonly used procedures: Smith-Petersen osteotomy, pedicle subtraction osteotomy, and vertebral column resection. Familiarity with the expected imaging appearance and commonly encountered complications seen on postoperative imaging studies following correction osteotomies is crucial for accurate image interpretation.
\end{abstract}

ABBREVIATIONS: $\mathrm{BDBO}=$ bone-disc-bone osteotomy; $\mathrm{PSO}=$ pedicle subtraction osteotomy; $\mathrm{SPO}=$ Smith-Petersen osteotomy; SVA = sagittal vertical axis; $\mathrm{VCR}=$ vertebral column resection

A dult spinal deformity can be either the result of progression of conditions present in childhood/adolescence or new onset secondary to degenerative changes, which is known as de novo degenerative scoliosis. ${ }^{1,2}$ There are many conditions that can lead to spinal deformity, including trauma, cancer, and osteoporosis and congenital, postsurgical, and idiopathic causes. Scoliosis is defined as $\geq 10^{\circ}$ of coronal spinal curvature measured by the Cobbs angle method. ${ }^{3}$ In 2006, the Scoliosis Research Society published an initial attempt to classify adult spinal deformity on the basis of the King/Moe and Lenke classification systems ${ }^{4}$; however, both of these well-known classification systems were originally developed for adolescent idiopathic scoliosis, and applying this system to adult spinal deformity was found to be suboptimal. This is because the treatment of adult spinal deformity has been shown to be driven by pain and disability in contrast to adolescent idiopathic scoliosis, which is primarily driven by coronal/cos-

From the Departments of Radiology (T.T., S.M.), Neurosurgery (D.K.), and Orthopedic Surgery (D.P.), University of Minnesota, Minneapolis, Minnesota.

An abstract "Sagittal Balance Correction Osteotomies: What Radiologists Should Know" was presented at the American Society of Spine Radiology Annual Symposium, February 23-26, 2017; San Diego, California as an electronic poster. Part of the material was presented as an oral presentation, "Implementation of the Schwab-Scoliosis Research Society Classification for Radiographic Measurement of Adult Spinal Deformity-What the Surgeon Wants to Know?" at the American Society of Spine Radiology Annual Symposium, February 18-21, 2016; Bonita Springs, Florida, which subsequently was awarded best nonmentored diagnostic presentation.

Please address correspondence to Takashi Takahashi, MD, MS, Department of Radiology, University of Minnesota, 20 Delaware St SE, MMC 292 4, Minneapolis, MN 55455; e-mail: takas005@umn.edu

-- Indicates open access to non-subscribers at www.ajnr.org

http://dx.doi.org/10.3174/ajnr.A5444 metic deformity. ${ }^{5}$ Surgical treatment of adolescent idiopathic scoliosis depends on the curve type and magnitude and is also affected by the degree of progression, skeletal maturity, cosmesis, and pain. ${ }^{6}$ An operation is typically performed for primary curves that have a Cobb angle of $>45^{\circ} .^{7,8}$ Surgeons vary in opinion regarding the levels to be fused within the general guidelines. These levels will depend on the major curve, shoulder balance, amount of correction desired, stiffness of the curve, side-bending radiographs, and clinical examination.

In recent years, sagittal spinopelvic alignment has been shown to correlate with a patient's pain and disability and is a primary determinant of health-related quality-of-life measures. ${ }^{9}$ Surgical treatment of a deformity can be beneficial in the appropriately selected patient. Clinical improvement has been demonstrated in studies in which sagittal imbalance was corrected. ${ }^{10,11}$ The Scoliosis Research Society Adult Deformity Committee subsequently developed a new classification system to address these pertinent features of adult spinal deformity in 2012 based on the work of Schwab et $\mathrm{al}^{9,12-14}$ and Bess et al. ${ }^{15}$ This classification system has shown excellent inter- and intrarater reliability on its validation study. ${ }^{16}$ Spine surgeons obtain preoperative and postoperative 36-inch standing full spine radiographs in the adult patient to primarily assess the following parameters: sagittal vertical axis (SVA), pelvic incidence minus lumbar lordosis, pelvic tilt, and coronal curve type. ${ }^{14}$

Until very recently, spinopelvic alignment has not been emphasized in the radiology literature. ${ }^{17}$ Glassman et al ${ }^{18}$ suggested that coronal balance correction is not as important as restoration of sagittal balance. There are various surgical techniques to correct sagittal imbalance, including various types of osteotomies. 
Knowledge about these operations and how they appear on imaging is critical for radiologists interpreting spine imaging to optimally report the findings. The purpose of this article was to summarize the 3 most widely used types of sagittal balance-correction osteotomies: Smith-Petersen osteotomy (SPO), pedicle subtraction osteotomy (PSO), and vertebral column resection (VCR), with an additional brief discussion of their derivatives or related uncommon procedures.

\section{Spinopelvic Measurements}

SVA. In the Scoliosis Research Society-Schwab Spinal Deformity Classification System evaluates global spinal alignment only in the sagittal plane by using the sagittal vertical axis. This is a measure of the horizontal distance between the $\mathrm{C} 7$ plumb line and the posterosuperior corner of the $\mathrm{S} 1$ endplate. The $\mathrm{C} 7$ plumb line is a vertical line drawn downward from the center of the $\mathrm{C} 7$ vertebral body, parallel to the vertical edge of the film. ${ }^{19}$ The distance is
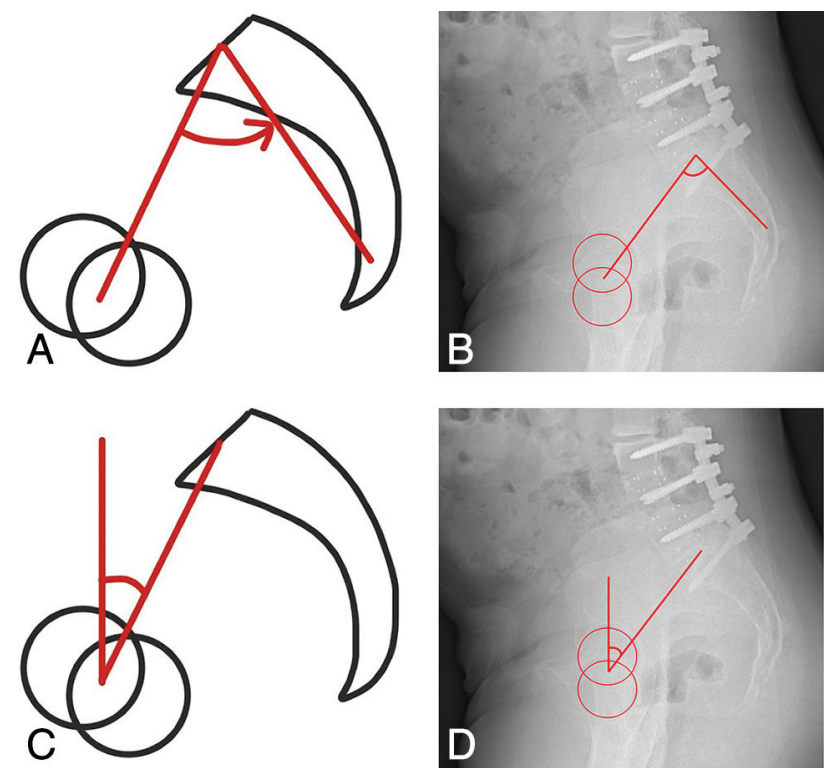

FIG 1. Schematic $(A)$ and radiographic measurement $(B)$ of pelvic incidence: an angle between a line drawn perpendicular to the middle of the superior sacral endplate and a line joining from the center of femoral heads to the center of the superior sacral endplate. Schematic $(C)$ and radiographic measurement $(D)$ of pelvic tilt: an angle measured between the lines connecting the center of the superior endplate of S1 to the center of femoral heads from its vertical perpendicular line. considered positive when the $\mathrm{C} 7$ plumb line is located anterior to the posterosuperior corner of S1. In the pediatric population, the SVA is considered abnormal in either the positive or negative direction when it is $>2 \mathrm{~cm}$ in absolute value. However, in adult spinal deformity, only the positive direction is of clinical concern. In this classification, the $\mathrm{C} 7$ plumb line is considered abnormal when it is located anterior to the posterosuperior corner of the $\mathrm{S} 1$ vertebral body at $>4 \mathrm{~cm}$. It is classified as positive when between 4 and $9.5 \mathrm{~cm}$ and very positive if $>9.5 \mathrm{~cm}$.

Pelvic Incidence-Lumbar Lordosis Mismatch. Pelvic incidence is an angle between a line drawn perpendicular to the middle of the superior sacral endplate and a line joining from the center of the femoral heads to the center of the superior sacral endplate (Fig 1). This is a measure of pelvic depth and is a patientspecific parameter that determines the native sagittal contour. In the Scoliosis Research Society classification, lumbar lordosis is measured from the superior endplate of L1 to the superior endplate of S1 using the Cobbs angle technique. When pelvic incidence minus lumbar lordosis is $\geq 10^{\circ}$, a study has shown that patients had a 10 times greater risk for undergoing revision surgery if such malalignment is maintained after a lumbar fusion operation. ${ }^{20}$

Pelvic Tilt. Pelvic tilt is an angle measured between a line connecting the center of the superior endplate of S1 to the center of the femoral heads, relative to a vertical perpendicular line (Fig 1). This measure is used to assess pelvic version, typically retroversion, which is a compensation mechanism to maintain spinal alignment. The retroversion is manifested by an increase in the pelvic tilt angle.

\section{Sagittal Balance-Correction Osteotomies}

The surgical correction technique of global positive sagittal balance can be considered as creation/restoration of more lordosis in the spine. In advanced cases, attaining such a goal requires osteotomies of the vertebrae. The more parts of the vertebrae resected, the more regional lordosis created (Table). There are various named osteotomies: Smith-Petersen osteotomy, pedicle subtraction osteotomy, and vertebral column resection are the paradigms of these procedures in order of increasing surgical complexity. ${ }^{2}$ Recently, Schwab et $\mathrm{al}^{21}$ proposed an anatomic-based spinal osteotomy classification. This approach uses grade 1 through 6 based on how much bone is resected. In this classification, a

Summary of sagittal balance-correction osteotomy

\begin{tabular}{|c|c|c|c|}
\hline & SPO/Ponte & PSO Category & VCR \\
\hline Schwab grade & 1 and 2 & 3 and 4 & 5 and 6 \\
\hline Resection area & Posterior element only & Included part of vertebral body & Entire vertebra \\
\hline Indication & $\begin{array}{l}\text { Long, gradual, rounded kyphosis, eg, } \\
\text { Scheurmann kyphosis }\end{array}$ & $\begin{array}{l}\text { Sharp, focal kyphosis with fixed disc } \\
\text { space, ie, SPO not applicable }\end{array}$ & $\begin{array}{l}\text { Sharp, focal kyphosis at } \\
\text { thoracic vertebra } \\
\text { Hemivertebra resection } \\
\text { Vertebral tumor resection }\end{array}$ \\
\hline Need disc space mobility? & Yes & No & No \\
\hline Sharp angular kyphosis correction? & No & Yes & Yes \\
\hline Thoracic spine correction? & No & No & Yes \\
\hline Kyphotic curvature correction & $\sim 10^{\circ} /$ level & $30^{\circ}-40^{\circ} /$ level & $45^{\circ}-70^{\circ}$ \\
\hline Indicated SVA (cm) & $>6-8 \mathrm{~cm}$ but $<10 \mathrm{~cm}$ (positive SVA) & $>10-12 \mathrm{~cm}$ (very positive SVA) & \\
\hline $\begin{array}{l}\text { Mean neurologic/overall } \\
\text { complication rate }(\%)^{27}\end{array}$ & $2.1 / 40.4$ & $9.1 / 38.5$ & $14.3 / 39$ \\
\hline
\end{tabular}



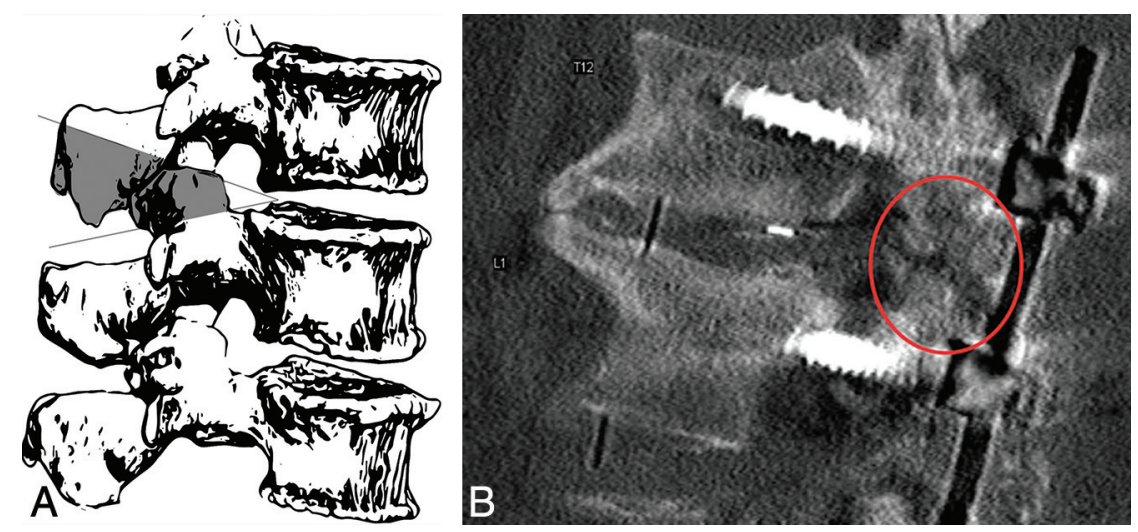

FIG 2. A, Schematic rendering of an SPO. Osteotomy of the posterior element, including wide resection of the facet joint. B, A 52-year-old man with a history of lumbar spinal fusion instrumentation at an outside institution who underwent sagittal correction surgery including an L3 PSO (not shown) and a T12-L1 SPO. This is a magnified image focusing on T12-L1 off the midline. The image demonstrates the T12 inferior articular facet and the L1 superior articular facet resections (circle) in addition to ligamentum flavum resection and bone grafts that were placed.
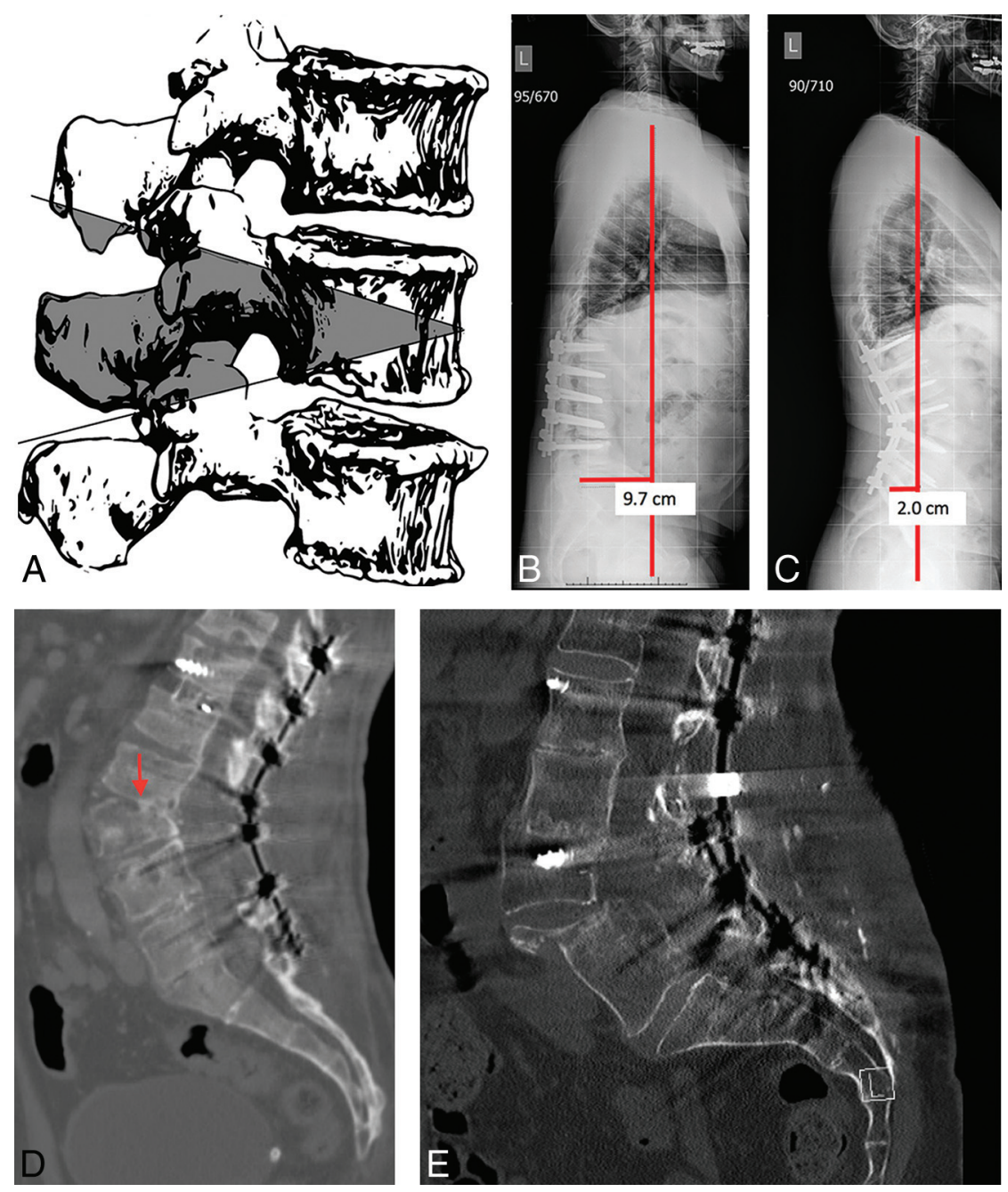

FIG 3. A, Schematic rendering of PSO. This is a posterior closing wedge osteotomy with resection of the posterior column, both pedicles, and part of the vertebral body. B, A 63-year-old man with prior postsurgical change of $72-\mathrm{L} 4$ fusion instrumentation with very positive global sagittal imbalance $(S V A=9.7 \mathrm{~cm}) . C$, The same patient after L3 PSO and fusion instrumentation extension both cranially and caudally. The SVA is now within normal limits $(2.0 \mathrm{~cm}) . D$, The same patient with a CT midsagittal bone window image demonstrating resection of the part of the $L 3$ vertebral body extending to the superior endplate (arrow) with closure osteotomy at L3, consistent with pedicle subtraction osteotomy. This should not be mistaken for a posterior wedge compression fracture. $E$, A patient with a history of lumbar spinal fusion instrumentation, including complete intervertebral disc space fusion across L4-L5, underwent an L4 PSO and subsequently developed a fracture through the L4 vertebral body subjacent to the superior endplate, with resultant anterior subluxation of the superior fragment and $\mathrm{L} 3$ vertebral body relative to a dominant $\mathrm{L} 4-\mathrm{L} 5$ vertebral body fusion mass fragment. 
modifier may be added on the basis of the surgical approach level beyond the destabilization, which is either posterior approach or combined anterior and posterior approach.

\section{SPO and Like Procedures}

This category encompasses Schwab classification of grades 1 and 2 osteotomy categories. Grades 1 and 2 refer to partial and complete facet resection, respectively. The paradigm osteotomy under this category is the Smith-Petersen osteotomy.

SPO. SPO was originally described for correction of flexion deformity in rheumatoid arthritis, in which ankyloses of the articular process and the adjacent spinous processes were present. ${ }^{22}$ SPO is also referred to as extension osteotomy. ${ }^{23}$ It is a posterior column closing wedge osteotomy technique involving resection of the lamina, posterior ligaments, and facet joints (Fig 2). The osteotomy site is then closed by adjusting the operating table into extension or compression on posterior spinal instrumentation, resulting in posterior column shortening.

Polysegmental Osteotomy. Polysegmental osteotomy involves removal of the superior and inferior articular processes and the interlaminar space adjacent to the articular processes. This is performed at multiple levels to create the necessary amount of lordosis. The original SPO sometimes achieved its sagittal balance correction via destabilization of the anterior tension band, which resulted in a risk of vascular and gastrointestinal complications. Therefore, this technique was developed in an attempt to cause less disruption of the anterior column than occurred from the originally described Smith-Petersen osteotomy. ${ }^{24,25}$

Ponte Procedure. The Ponte procedure refers to the resection of multiple facets and spinous processes with posterior decompression along unfused regions of kyphotic deformity in Scheurmann kyphosis. ${ }^{25,26}$ This technique is a more commonly used posterior column osteotomy than the originally described SPO; however, the name "SPO" has remained to describe a spectrum of posterior column osteotomies categorized generally under the grade 2 group including the Ponte procedure. ${ }^{25}$ Thus, nomenclature confusion can occur at times. In this article, SPO terminology also refers to the Ponte procedure as in other literature.

In SPO, a mobile anterior disc is required for correction. SPO is generally considered when the sagittal vertical axis is $6-8 \mathrm{~cm}$ positive. ${ }^{27}$ SPO is especially suitable for long, gradual, rounded kyphosis - that is, Scheurmann kyphosis. SPO can achieve $5^{\circ}-10^{\circ}$ of lordosis per level of correction. ${ }^{28}$ It is estimated that for every 1 $\mathrm{mm}$ of facet resection, $1^{\circ}$ of correction is obtained.

The benefit of SPO is that it is technically easier and safer than higher grade osteotomies. For a comparable degree of correction, 3-level SPO resulted in roughly half the blood loss compared with single-level PSO. ${ }^{29}$ The disadvantage of SPO is that it provides fewer sagittal plane corrections than higher level osteotomies and may create coronal decompensation in contrast to other sagittal balance-correction osteotomies. SPO is also not suitable for sharp angular kyphosis correction. Because SPO uses the disc space as a fulcrum, this technique is inapplicable when the disc space lacks flexibility.
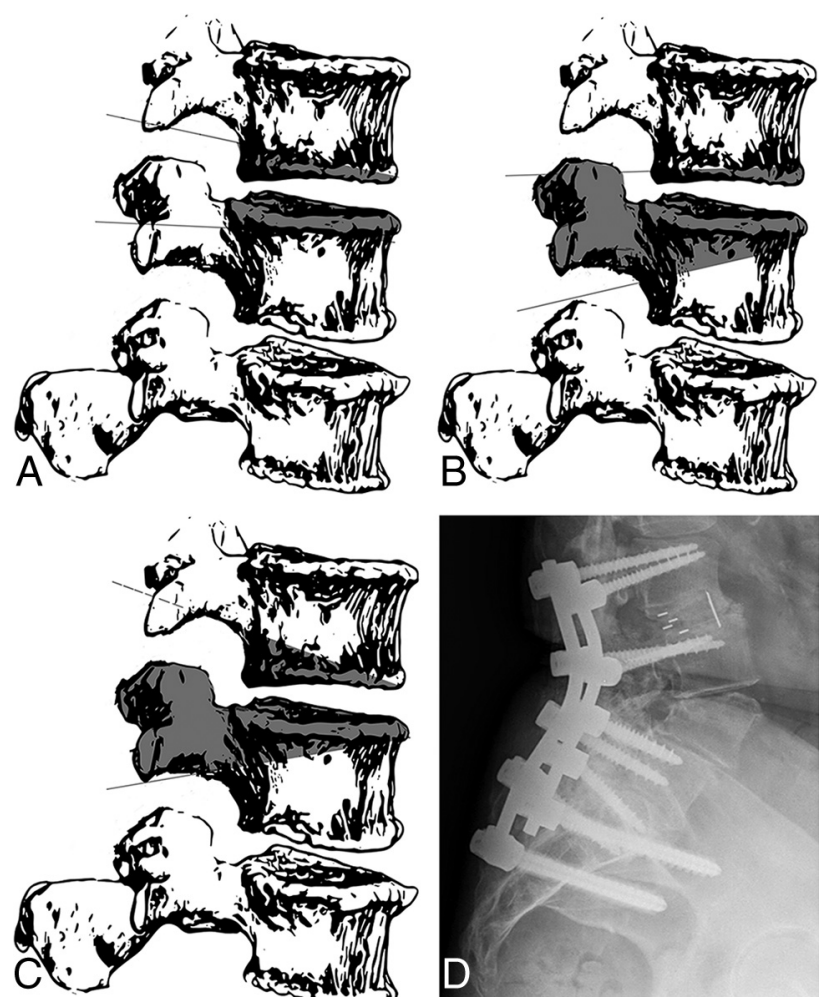

FIG 4. $A, B D B O$ type 1. This osteotomy involves the resection of the inferior portion of the target vertebra, along with the disc and superior endplate below it. B, BDBO type 2, also known as extended PSO. This osteotomy extends PSO cranially to involve the disc and inferior endplate of the vertebra above it. C, BDBO type 3. Closing wedge osteotomies are performed at levels both above and below the targeted disc level, with the osteotomy extending to just inferior to the transverse processes of the both levels. $D$, Lateral view plain radiograph demonstrates an extended PSO (BDBO type 2) at $\mathrm{L} 4$ where the PSO extends into the posterior two-thirds of the superior endplate.

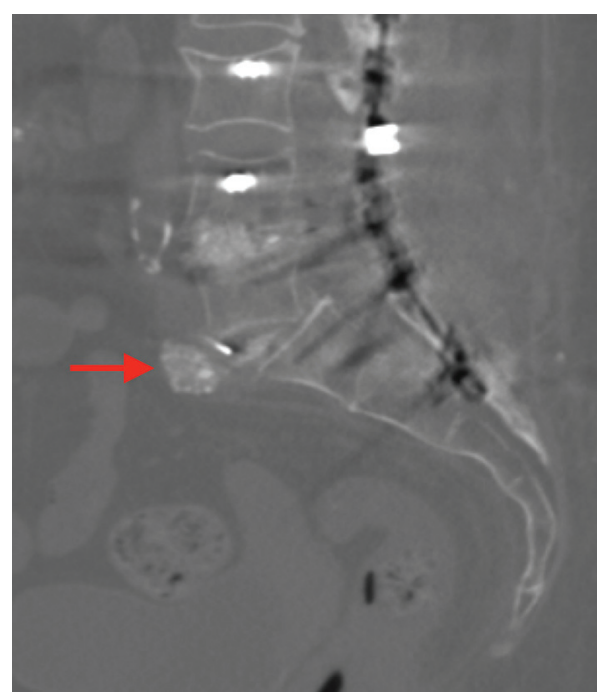

FIG 5. A patient with prior fusion instrumentation from $L 2$ to the sacrum who underwent 2-level transforaminal lumbar intervertebral fusion at L3-L4 and L4-L5. There was inadvertent intraoperative anterior longitudinal ligament disruption at L5-S1. This essentially resulted in an anterior opening osteotomy effect along with a SmithPetersen osteotomy posterior closing osteotomy (ie, X-osteotomy) There is an unintentional anteriorly extruded intervertebral disc graft at this level (arrow). 

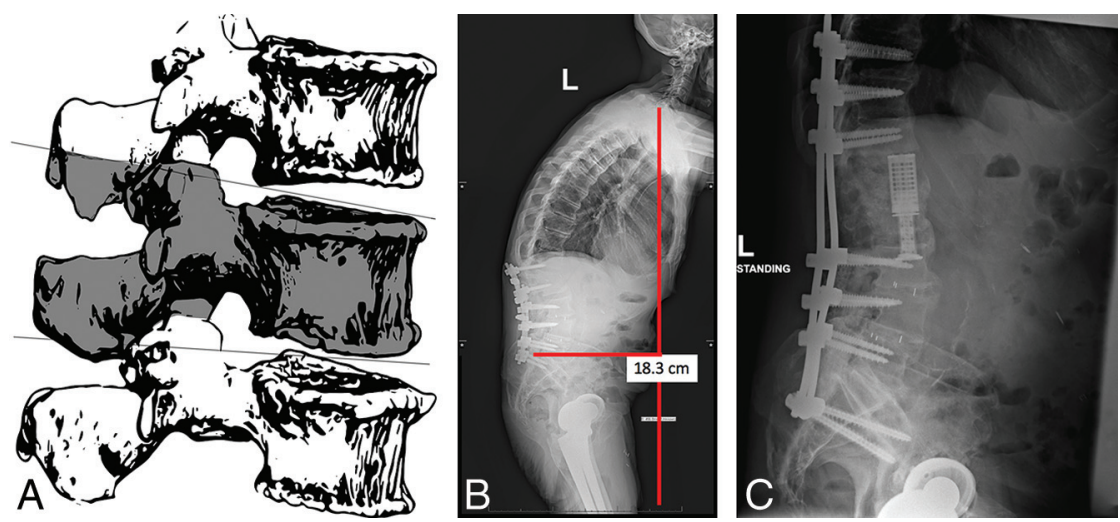

FIG 6. $A$, Schematic drawing of single-level VCR. The entire vertebral body is resected. $B, A$ 61-year-old man with postoperative discitis/osteomyelitis with a very positive SVA $(>18 \mathrm{~cm})$. C, The same patient underwent 2-level (L1 and L2) VCR with extension of posterior fusion instrumentation.

\section{PSO and Like Procedures}

In the grade 3 category of the Schwab classification, the osteotomy involves part of the posterior vertebral body and posterior elements, including the pedicles. The paradigmatic procedure of this category is a pedicle subtraction osteotomy.

PSO. In 1985, the pedicle subtraction osteotomy was described by Thomasen. ${ }^{30}$ It was originally described for the treatment of disabling kyphosis in patients with ankylosing spondylitis. PSO is a posterior wedge-type osteotomy with resection of the posterior column, both pedicles, and part of the vertebral body, followed by closure osteotomy (Fig 3). In PSO, the anterior cortex is used as a hinge. Therefore, PSO is typically used for patients with sharp or angular kyphosis as well as at levels lacking anterior flexibility where SPO is inapplicable. ${ }^{25,31}$ Analogous to the SPO, the PSO has been also referred to by various alternatives, including closing wedge osteotomy, eggshell osteotomy, and transpedicular wedge procedure. $^{25}$

On imaging, PSO may be mistaken for a posterior wedge compression fracture if one is not aware of this type of surgery. PSO is generally indicated for correction of SVAs of $>10-12$ $\mathrm{cm}$, and it can provide $30^{\circ}-40^{\circ}$ of lordosis correction on average. ${ }^{31,32}$ In this technique, along with pedicle screw posterior fixation, wide laminectomies are performed at adjacent levels to protect the exiting nerve roots. Interbody fusion at levels above and below the osteotomy may be performed to avoid pseudoarthrosis.

PSO provides the main advantage of more effective focal kyphosis correction than SPO, a mean correction of $32.6^{\circ}$ per level of PSO in contrast to $10.2^{\circ}$ per level of SPO. ${ }^{25}$ The mean neurologic complication rate is higher than that of SPO: 9.1\% in PSO versus $2.1 \%$ in SPO. $^{25}$

Bone-Disc-Bone Osteotomy. In the grade 4 category of the Schwab classification, surgical resection extends to involve a disc and its adjacent endplates. Extended PSO is a type of bone-discbone osteotomy (BDBO), which is categorized under this grade. There are 3 types of $\mathrm{BDBO}$, with lordosis correction ranging from $35^{\circ}$ to $60^{\circ}$ (Fig 4 ). ${ }^{32}$ In type 1 , the inferior portion of the target vertebra, along with the disc and superior endplate below it, is involved. In type 2 or extended PSO, PSO is extended to involve the disc and inferior endplate of the vertebra above it. In type 3, closing wedge osteotomies are performed at levels both above and below the targeted disc level, with the osteotomy extending to just inferior to the transverse processes of both levels. $^{33}$

$\mathrm{BDBO}$ is performed when there is severe sagittal imbalance, with the apex or center of the rotational axis located at the disc space. Advantages of BDBO include a higher degree of lordosis correction beyond what SPO can provide and a decreased pseudoarthorosis rate compared with SPO. The disadvantage of $\mathrm{BDBO}$ is that it can create a focal angular hyperlordosis, sometimes resulting in symptomatic spinal stenosis.

X-Osteotomy/Closing-Opening Wedge Osteotomy. Another special form of pedicle subtraction osteotomy, which is not explicitly defined as a part of the Schwab classification, is the X-osteotomy. ${ }^{34}$ This involves posterior column closing and anterior column opening; hence, it is also referred to as closing-opening wedge osteotomy. Park et $\mathrm{al}^{35}$ refer to this procedure as "fish-mouth PSO," which helps understand this procedure as indeed an extension/variation of the PSO. Closing-opening wedge osteotomy starts out as closing wedge osteotomy (ie, PSO, but in addition, the anterior wall of the vertebral body is fractured using an osteotome; Fig 5). It hinges on the middle column of the spine closing posteriorly and wedging open anteriorly, leaving an anterior column deficit, as opposed to a VCR, in which the anterior deficit is typically filled with a cage or a structural graft. PSO has a limitation due to the anatomy and morphology of the anterior cortex of the vertebral body of the apex potentially restricting the amount of attainable single-level PSO angle correction. Closingopening wedge osteotomy may be an option in place of 2-level PSO in such situations.

VCR. Vertebral column resection is often used in vertebral tumor resection; however, this technique is also a form of the most extensive type of osteotomy. VCR can achieve correction of kyphotic and coronal curves, in the range of $45^{\circ}-70^{\circ}$, depending on the case and the degree of correction required. ${ }^{36-39}$ Posterior VCR is primarily used in the thoracic and thoracolumbar spine for the treatment of sharp, angular kyphotic deformity in sagittal spinal-balance correction. ${ }^{25}$ In VCR, $\geq 1$ vertebral segment is entirely resected, including the posterior elements, entire vertebral body, and the adjacent discs. In the Schwab classification system, grade 5 refers to single-level VCR and grade 6 refers to $\geq 2$ levels of VCR (Fig 6).

The major risk of VCR is the potential for neurologic complications, either from direct injury during the operation or secondary to subsequent subluxation of the spinal column. The mean neurologic complication rate is $14.3 \% .^{25}$ This is used only in extreme cases when there is not a good alternative.

\section{CONCLUSIONS}

Global sagittal balance correction has shown correlation with positive clinical outcome. Some of these correction techniques, in 
particular osteotomies, may appear as posterior wedge compression fractures if one is not aware of the surgical techniques. Hence, it is crucial for radiologists who read spine imaging to be familiar with these techniques and how these postoperative changes appear on imaging.

\section{REFERENCES}

1. Birknes JK, Harrop JS, White AP, et al. Adult degenerative scoliosis: a review. Neurosurgery 2008;63:94-103 Medline

2. Youssef JA, Orndorff DO, Patty CA, et al. Current status of adult spinal deformity. Global Spine J 2013;3:51-62 CrossRef Medline

3. Aebi M. The adult scoliosis. Eur Spine J 2005;14:925-48 CrossRef Medline

4. Lowe T, Berven SH, Schwab FJ, et al. The SRS classification for adult spinal deformity: building on the King/Moe and Lenke classification systems. Spine 2006;31:S119-25 CrossRef Medline

5. Bess S, Boachie-Adjei O, Burton D, et al; International Spine Study Group. Pain and disability determine treatment modality for older patients with adult scoliosis, while deformity guides treatment for younger patients. Spine 2009;34:2186-90 CrossRef Medline

6. Agabegi SS, Kazemi N, Sturm PF, et al. Natural history of adolescent idiopathic scoliosis in skeletally mature patients: a critical review. J Am Acad Orthop Surg 2015;23:714-23 CrossRef Medline

7. Sy N, Bettany-Saltikov J, Moramarco M. Evidence for conservative treatment of adolescent idiopathic scoliosis: update 2015 (mini-review). Cur Pediatr Rev 2016;12:6-11 CrossRef Medline

8. Weinstein SL, Dolan LA, Cheng JC, et al. Adolescent idiopathic scoliosis. Lancet 2008;371:1527-37 CrossRef Medline

9. Schwab FJ, Blondel B, Bess S, et al; International Spine Study Group (ISSG). Radiographical spinopelvic parameters and disability in the setting of adult spinal deformity: a prospective multicenter analysis. Spine 2013;38:E803-12 CrossRef Medline

10. Kim YJ, Bridwell KH, Lenke LG, et al. Results of lumbar pedicle subtraction osteotomies for fixed sagittal imbalance: a minimum 5-year follow-up study. Spine 2007;32:2189-97 CrossRef Medline

11. Kiaer T, Gehrchen M. Transpedicular closed wedge osteotomy in ankylosing spondylitis: results of surgical treatment and prospective outcome analysis. Eur Spine J 2010;19:57-64 CrossRef Medline

12. Schwab FJ, Smith VA, Biserni M, et al. Adult scoliosis: a quantitative radiographic and clinical analysis. Spine 2002;27:387-92 CrossRef Medline

13. Schwab F, Farcy JP, Bridwell K, et al. A clinical impact classification of scoliosis in the adult. Spine 2006;31:2109-14 CrossRef Medline

14. Schwab F, Ungar B, Blondel B, et al. Scoliosis Research SocietySchwab Adult Spinal Deformity Classification: a validation study. Spine 2012;37:1077-82 CrossRef Medline

15. Bess S, Schwab F, Lafage V, et al. Classifications for adult spinal deformity and use of the Scoliosis Research Society-Schwab Adult Spinal Deformity Classification. Neurosurg Clin North Am 2013;24: 185-93 CrossRef Medline

16. Sengupta DK. Re: Schwab F, Ungar B, Blondel B, et al: Scoliosis Research Society-Schwab Adult Spinal Deformity Classification—a validation study—Spine 2012;37:1077-82. Spine (Phila Pa 1976) 2012;37:1790 CrossRef Medline

17. Murtagh RD, Quencer RM, Uribe J. Pelvic evaluation in thoracolumbar corrective spine surgery: how I do it. Radiology 2016;278: 646-56 CrossRef Medline

18. Glassman SD, Berven S, Bridwell K, et al. Correlation of radiographic parameters and clinical symptoms in adult scoliosis. Spine 2005;30:682-88 CrossRef Medline

19. Diebo BG, Varghese JJ, Lafage R, et al. Sagittal alignment of the spine: what do you need to know? Clin Neurol Neurosurg 2015;139: 295-301 CrossRef Medline

20. Rothenfluh DA, Mueller DA, Rothenfluh E, et al. Pelvic incidencelumbar lordosis mismatch predisposes to adjacent segment disease after lumbar spinal fusion. Eur Spine J 2015;24:1251-58 CrossRef Medline

21. Schwab F, Blondel B, Chay E, et al. The comprehensive anatomical spinal osteotomy classification. Neurosurgery 2014;74:112-20; discussion 120 CrossRef Medline

22. Smith-Petersen MN, Larson CB, Aufranc OE. Osteotomy of the spine for correction of flexion deformity in rheumatoid arthritis. Clin Orthop Relat Res 1969;66:6-9 Medline

23. Lu DC, Chou D. Flatback syndrome. Neurosurg Clin N Am 2007;18: 289-94 CrossRef Medline

24. Sansur CA, Fu KM, Oskouian RJ Jr, et al. Surgical management of global sagittal deformity in ankylosing spondylitis. Neurosurg Focus 2008;24:E8-94 CrossRef Medline

25. Dorward IG, Lenke LG. Osteotomies in the posterior-only treatment of complex adult spinal deformity: a comparative review. Neurosurg Focus 2010;28:E4 CrossRef Medline

26. Geck MJ, Macagno A, Ponte A, et al. The Ponte procedure: posterior only treatment of Scheuermann's kyphosis using segmental posterior shortening and pedicle screw instrumentation. J Spinal Disord Tech 2007;20:586-93 CrossRef Medline

27. Kim KT, Park KJ, Lee JH. Osteotomy of the spine to correct the spinal deformity. Asian Spine J 2009;3:113-23 CrossRef Medline

28. Yang BP, Ondra SL, Chen LA, et al. Clinical and radiographic outcomes of thoracic and lumbar pedicle subtraction osteotomy for fixed sagittal imbalance. J Neurosurg Spine 2006;5:9-17 CrossRef Medline

29. Cho KJ, Bridwell KH, Lenke LG, et al. Comparison of Smith-Petersen versus pedicle subtraction osteotomy for the correction of fixed sagittal imbalance. Spine (Phila Pa 1976) 2005;30:2030-37; discussion 2038 CrossRef Medline

30. Thomasen E. Vertebral osteotomy for correction of kyphosis in ankylosing spondylitis. Clin Orthop Relat Res 1985:142-52 Medline

31. Bridwell KH. Decision making regarding Smith-Petersen vs. pedicle subtraction osteotomy vs. vertebral column resection for spinal deformity. Spine 2006;31:S171-78 CrossRef Medline

32. Enercan M, Ozturk C, Kahraman S, et al. Osteotomies/spinal column resections in adult deformity. Eur Spine J 2013;22(suppl 2): S254-64 CrossRef Medline

33. Domanic U, Talu U, Dikici F, et al. Surgical correction of kyphosis: posterior total wedge resection osteotomy in 32 patients. Acta Orthop Scand 2004;75:449-55 CrossRef Medline

34. Vaccaro AR, Rothman RH, Albert TJ. 70 posterior osteotomies: posterior Smith-Peterson, pedicle subtraction, and vertebral column resection osteotomy techniques. In: Vaccaro AR, Rothman RH, Albert TJ, eds. Spine Surgery. Stuttgart: Georg Thieme Verlag; 2016:1-8

35. Park JH, Hyun SJ, Kim KJ, et al. Comparative study between pedicle subtraction osteotomy (PSO) and closing-opening wedge osteotomy (fish-mouth PSO) for sagittal plane deformity correction. Spine (Phila Pa 1976) 2017;42:E899-905 CrossRef Medline

36. Demirkiran G, Dede O, Karadeniz E, et al. Anterior and posterior vertebral column resection versus posterior-only technique: a comparison of clinical outcomes and complications in congenital kyphoscoliosis. Clin Spine Surg 2017;30:285-90 CrossRef Medline

37. Lenke LG, Newton PO, Sucato DJ, et al. Complications after 147 consecutive vertebral column resections for severe pediatric spinal deformity: a multicenter analysis. Spine 2013;38:119-32 CrossRef Medline

38. Zhang Z, Wang H, Shangguan L. Posterior 2-level vertebral column resection for the treatment of progressive rotational dislocation in kyphoscoliotic deformities. World Neurosurg 2016;88: 428-32 CrossRef Medline

39. Wang Y, Xie J, Zhao Z, et al. Perioperative major non-neurological complications in 105 patients undergoing posterior vertebral column resection procedures for severe rigid deformities. Spine 2015; 40:1289-96 CrossRef Medline 